\title{
Abordagem psicossociológica sobre ameaças e seus usos sociais*
}

Recebido: 13.04 .18 Aprovado: 03.08.18
Denise Jodelet**

\section{Apresentação}

ste texto apresenta alguns conjuntos de questões sobre um novo domínio de pesquisa, a respeito do qual a psicologia social e as ciências sociais começam a se debruçar: as ameaças sociais. Tive o prazer de iniciar reflexões sobre esse tema em dois colóquios. O primeiro ocorrido, há três anos, na Universidade Paris V (René Descartes), cujas atas acabam de ser publicadas (Caillaud et alii, 2017). Organizei o segundo, na Fondation Maison des Sciences de l'Homme de Paris, com meus colegas Ewa Drozda Sendovska, da Universidade de Paris V, e Jorge Vala, da Universidade de Lisboa. Esse colóquio interdisciplinar reuniu outros psicólogos sociais e participantes proveniente das áreas de sociologia, antropologia, economia, biologia e ecologia.

\section{O surgimento de uma nova área de estudo:} as ameaças

"Ameaça" é uma palavra que aparece de tempos em tempos no espaço social e midiático. Atualmente, refere-se a fenômenos que envolvem as vulnerabilidades sociais e um acúmulo de eventos perturbadores, suscetíveis de provocar um sentimento de derrocada. Assim, agora, a ameaça deve ser considerada como uma categoria diferente da categoria de risco, à qual, muitas vezes, foi associada. Uma categoria em que a proporção de ansiedade e imaginação favorece as projeções apocalípticas e as sobreposições, contribuindo assim para a criação de um espaço para as reflexões sobre a história desses fenômenos.

Mas, enquanto os trabalhos sobre riscos em diferentes áreas (saúde, meio ambiente, política etc.) são agora domínios correntes para uma discussão sobre sua repercussão no plano individual e coletivo, bem como os procedimentos de precaução e prevenção - cuja defesa, às vezes, é questionada por causa dos efeitos que podem impactar sobre o público e as instituições (Breakwell, 2010) -, os trabalhos relativos às ameaças são bem menos numerosos.

\footnotetext{
* Conferência

magna de abertura

do segundo

semestre letivo

do Departamento

de Sociologia

da Universidade

de Brasília (SOL/

UnB), ocorrida

em 30 de agosto

de 2017. Titulo

original: Approche

psychosociologique des menaces et de leurs usages sociaux.

Tradução de Tânia

Mara Campos de Almeida, professora adjunta do (SOL) UnB).
** Denise Jodelet é diretora de estudos da École des Hautes Études en Sciences Sociale (Ehess), Paris, França, aposentada. É presidente da Rede Mundial Serge Moscovici, Fondation Maison des Sciences de l'Homme, Paris, França.


Esse tema foi proposto a um grupo de pesquisadores - do qual faço parte -, que se dedica a aprofundar essa categoria, que hoje constitui uma categoria de uso corrente, mas cujas dimensões são ao mesmo tempo psicológicas, sociais, religiosas e políticas, bem como demandam uma abordagem transdisciplinar para o estudo dos domínios fundamentais da vida. Diversos trabalhos em psicologia social e cognitiva abordaram principalmente as relações interpessoais e intergrupais.

Tentarei mostrar que a abordagem das representações sociais pode contribuir para essa área de pesquisa, apoiando-me em minha experiência de pesquisa, na qual está presente a questão do risco, do perigo e da ameaça. Os campos relativos a esses estudos afetaram várias áreas:

i. na psicologia ambiental, com a gestão dos riscos ambientais, abordados mediante as representações institucionais, as tomadas de posição na esfera individual ou comunitária, os efeitos das mensagens políticas e midiáticas (Jodelet, 1996; 1998; 2001; Jodelet \& Scipion, 1992);

ii. na psicologia da saúde, onde encontrei as ameaças associadas à presença da loucura no espaço social, ao contágio da doença mental ou das doenças transmissíveis - notadamente a Aids - ou aquelas que subjazem à estigmatização das pessoas com transtornos psíquicos (Jodelet, 1989, 2011b; Jodelet \& Monforte, 1994); e

iii. na psicologia social, com o estudo das formas do medo e dos efeitos de sua manipulação política, ou aquela que a remete à alteridade e à construção dos perigos que ela apresenta (Jodelet, 1996, 2005, 2011a, 2015a).

A partir de minha experiência, de um lado, e com base nessas aquisições indiretamente relacionadas à questão da ameaça, de outro, tentarei formular algumas interrogações que assumirão, às vezes, a forma de provocação à reflexão e de convite para a ampliação e estruturação do campo de estudo das ameaças, que inclui os diversos setores das ciências humanas e sociais. As poucas reflexões que proponho partem das contribuições de uma corrente disciplinar - o estudo das representações sociais -, que situo como ponto central das ciências sociais.

Essa corrente de estudo aborda a forma como as pessoas comuns, as cultas e as estudiosas pensam a sua realidade cotidiana, elaboram a sua visão, o seu conhecimento, a sua interpretação do mundo, no âmbito das quais operam. Esse pensamento eminentemente social é construído a partir da experiência e de suas comunicações. Às vezes, o pensamento é construído sob o estatuto dos constrangimentos sociais, 
às vezes, em contraposição às imposições decorrentes do quadro da atividade, seja ele institucional, social, simbólico ou material. Neste pensamento social, reúnem-se os conhecimentos assimilados a partir da transmissão educacional, os saberes construídos sob a influência da posição social, do pertencimento cultural, da integração nos espaços de vida e ação, das conjunturas históricas, dos fluxos de informações, dos bombardeios midiáticos, a propósito dos quais Laplantine evoca o "prazer" das "grandes notícias catastróficas".

O jogo desta inscrição social, mesmo ideológica, na produção de representações também se aplica a produções tecnológicas e científicas. Basta observar o perfil dos debates que agitam a avaliação das contribuições científicas e das formulações que os ensaios da filosofia social propõem para pensar a modernidade e a pós-modernidade. Voltarei sobre o tema.

Por ora, gostaria de expor um certo número de pontos para esclarecer a noção de ameaça. Minha proposta é esboçar uma abordagem sobre a forma pela qual é realizado no espaço público o emprego da noção de ameaça em narrativas, em representações que circulam nas comunicações e nas trocas sociais diárias, em debates que animam as esferas científicas, políticas, midiáticas, bem como suas implicações e consequências para a vida social.

Isso supõe esclarecer as acepções da noção de ameaça e seu posicionamento em relação a outros termos aos quais ela foi associada. Ao realizá-lo, será possível identificar as dimensões subjacentes, o mal e o medo que dão referência aos seus tons, participando das ansiedades contemporâneas, e será possível esboçar o quadro de uma análise destinada a identificar os fenômenos e os processos que a ameaça coloca em jogo.

Desenvolvimento das referências

da noção de ameaça

Ao considerar a sucessão de textos sobre os riscos que envolvem a ecologia, as ciências e as técnicas, as ciências sociais, as mídias, as produções fictícias, quer sejam literárias ou cinematográficas, há uma evolução no uso da noção de ameaça. No início, utilizada simplesmente como anúncio de um possível perigo, a ameaça teve uma apropriação mais pronunciada e específica a partir do fim dos anos 1990, com o reconhecimento da gravidade e da amplitude dos problemas ambientais e sanitários e com o surgimento do terrorismo, apelando para elaborações de sentido mais discreto e sutil. Atualmente, a ameaça remete, insidiosamente, a um estado de catástrofe, resultando em uma visão do presente e do futuro cataclísmico, quase 
"apocalíptico", à qual são associados termos que suscitam ansiedade (Boy, 1999; Clavandier, 2004).

A título de exemplo, citarei um caso francês, aquele de um dossiê publicado pelo Le Magazine Littéraire (2015), antecipando a realização da "Cop-21". Este exemplo é interessante por um duplo sentido.

Por um lado, é observada - a partir dos principais textos éticos de autoria de Bertrand Russel, Karl Jaspers, Gunther Anders, Jonathan Schell, Hans Jonas, Edgar Morin etc., todos inspirados pela bomba atômica - a existência de títulos de obras que, desde os anos 2000, têm um tom trágico, catastrófico em relação ao destino dos homens. Aqui estão alguns dos títulos:

- Jared Diamond. Effondrement. Comment les sociétés décident de leur disparition ou de leur survie (Derrocada: como as sociedades decidem sobre o seu desaparecimento ou a sua sobrevivência). Collection "Essais". Paris: Folio, 2005.

- François Walter. Catastrophes. Une histoire culturelle - XVlème-XX lème siècles (Catástrofe. Uma história cultural - séculos XVI-XXI). Paris: Les Éditions du Seuil, 2008.

- Jean-Noël Lafargue. Les fins du monde. De l'Antiquité à nos jours (Os fins do mundo. Da Antiguidade aos dias atuais). Paris: Bourin François Éditeurs, 2012.

- Gunther Sanders. L'obsolescence de l'homme (A obsolescência do homem). Paris: Les Éditions Fario, 2012.

- Raphaël Stevens \& Pablo Servigne. Comment tout peut s'effondrer. Petit manuel de collapsologie à l'usage des générations présentes (Como tudo pode desmoronar. Pequeno manual de colapsologia para a utilização das gerações presentes). Paris: Les Éditions du Seuil, 2014.

- Hicham-Stéphane Afeissa. La fin du monde et de l'humanité. Essai de généalogie du discours écologique (O fim do mundo e da humanidade. Ensaio de genealogia do discurso ecológico). Paris: Presses Universitaires de France, 2014.

- Elisabeth Kolbert. La sixième extinction (A sexta extinção). Paris: Vuibert, 2015. 
- Jean-Paul Engélibert \& Raphaëlle Guidée. Utopie et catastrophe. Revers et renaissance de l'utopie. (Utopia e catástrofe. Reverso e renascimento da utopia). Rennes (FR): Presses Universitaires de Rennes, 2015 .

Por outro lado, esse quadro ilustra bem como os meios de comunicação moldam uma visão que, muitas vezes deletéria, provavelmente influenciará as posições do público, reforçando seus sentimentos ansiogênicos, sua suspeita frente às políticas públicas e suas demandas de proteção. Em comparação com uma desvalorização da ciência, essa visão também favorece a realização de discursos políticos que empregam a noção de ameaça para mobilizar a atenção e forjar uma visão que afeta a vida em seu conjunto, o que tentarei mostrar na sequência, sem antes examinar as dimensões com as quais justamente é possível abordar a noção de ameaça.

\section{Sobre algumas acepções}

da noção de ameaça

A noção de ameaça está geralmente associada a outros termos: risco, perigo, incômodo, aborrecimento, estresse, medo, pavor, terror, susto. Essa associação contribuiu para obscurecer seu significado, pois esses termos não se referem a fenômenos ou a processos da mesma ordem. Risco e perigo referem-se a uma exterioridade ao sujeito que a experimenta, real ou imaginária, mesmo que seja o sujeito ele mesmo que os provoque por sua conduta, como é, por exemplo, o caso do tabagismo, a prática de esportes radicais ou o desrespeito às prescrições médicas. Estresse, medo, pavor etc. designam um estado, um sentimento que o sujeito experimenta quando confrontado com algum risco ou perigo.

Os trabalhos sobre risco observam em suas análises essa distinção, sem contudo elucidar o status da ameaça. Mas essa situação modificou-se. Em decorrência da colaboração manifesta entre os órgãos de pesquisa e os de gestão, a modelagem de risco fornece os meios para uma abordagem transversal dos diferentes domínios em que são observados e estudados: saúde, meio ambiente, finanças, segurança, trabalho, sociedade, criminalidade, delinquência, guerra, terrorismo etc.; embora, no que diz respeito às ameaças, tem parecido difícil seguir essa mesma trajetória, e isso devido a diferentes razões.

A existência de deslizes semânticos, que identificam o termo ameaça com outros como risco, perigo, pavor, incômodo, estresse, medo etc., levou justamente o termo a perder qualquer especificidade em favor de um papel de noção "guarda-chu- 
va" ou de metáfora. Mas seus usos e abusos recentes demandam uma elaboração específica adaptada às diferentes áreas onde o jogo da ameaça toma diferentes formas. Para citar um exemplo atual: quando se passa das ameaças ocasionadas pela mudança climática àquelas que são representadas por ataques terroristas, os fenômenos e os processos que traduzem a noção não são mais próximos ou idênticos, exigem elaborações de significados bem mais elaborados e sutis. Além disso, os usos e abusos da noção no discurso social the conferem fisionomias incomensuráveis.

É então possível imaginar a realização de uma análise coerente e com alguma homogeneidade usando as diferentes disciplinas para criar uma estrutura que permita uma abordagem abrangente? Vou tentar contribuir tomando justamente essa direção, examinando como o senso comum constrói a noção e as ferramentas à sua disposição para realizá-lo. Para esse fim, retomarei os elementos das comunicações apresentadas nos dois colóquios organizados pela Universidade de Paris $V$, René Descartes e pela Fondation Maison des Sciences de l'Homme de Paris.

Primeiro, tentarei delimitar as acepções da noção de ameaça; em seguida, abordarei a questão das temporalidades da ameaça - ou melhor, das ameaças -, pois, como mostrarei, é impossível, ilusório pretender elaborar um modelo unitário para tratar os fenômenos que tomam na vida social formas concretas variadas, segundo suas escalas, seus processos, seus atores, seus alvos e seus problemas. Na verdade, esses fenômenos, que fazem parte de uma abordagem psicossociológica, podem ser diferenciados de acordo com sua natureza, sua origem, seu alvo, seu modo de ação, suas participações e seus efeitos individuais e coletivos, suas formas de enfrentá-los. Voltarei ao tema antes de discutir a questão das ameaças, que pode ir da defesa à negação e ao desafio.

\section{Elementos de definição: da palavra ao conceito}

Quando percorremos a literatura, ficamos impressionados com duas características. De um lado, o fato de que o termo ameaça é - como já disse - frequentemente confundido - ou assemelhado - com outros termos que engajam uma visão perturbadora de uma situação atual ou futura. De outro lado, se considerarmos como as ameaças são operacionalizadas e conceitualizadas em pesquisas experimentais, constataremos - conforme indicaram Thorisdottir e Jost (2011) - a falta de precisão das definições. Como definirmos a ameaça ou as ameaças para passarmos dos fenômenos sociais observados a um constructo teórico? 
Para clarificar os diferentes sentidos do termo ameaça, não é inútil partir das acepções correntes, na medida em que os modelos científicos da psicologia têm uma estreita relação com as conotações da linguagem comum e os conceitos de senso comum, como bem diz Harold Kelly:

Ignorar a bagagem da psicologia voltada ao senso comum nos levaria a privar-nos das vastas fontes de conhecimentos acumuladas no curso da história humana. A psicologia do senso comum constitui tanto um limite quanto um legado para a psicologia científica. Como tudo o que herdamos, temos pouca ou nenhuma escolha neste assunto. E, como todas as demais heranças, ao mesmo tempo em que cria constrangimentos e problemas, fornece-nos uma base útil e plena de potencialidades para o nosso crescimento e desenvolvimento (Kelly, 1992: 22).

Para examinar o uso do termo ameaça em francês, consultei os grandes dicionários da língua francesa Littré e Robert. Ambos insistem na dimensão interpessoal do regime da ameaça, considerada como a manifestação por meio da qual é evidenciada a qualquer um a raiva de alguém, com a intenção de fazer acreditar no mal que the pode ser causado. Associada a uma advertência, uma intimidação, uma chantagem, ela é a expressão do projeto de causar dano a outrem. Menos dramática, ela pode simplesmente supor um pacto ou um contrato social, instituindo uma condicionalidade na troca onde o dano anunciado vem em retaliação da não satisfação de um pedido ou de um desejo. Além disso, no uso corrente, ameaça é equivalente a colocar qualquer um em perigo, provocar-lhe o receio de algum mal. Ser ameaçado refere-se à existência de um perigo e à fragilidade de seu alvo. A referência ao perigo, ao mal e à vulnerabilidade é hoje ampliada nas preocupações que surgiram por causa das situações coletivas peculiares à nossa modernidade.

Vários autores que lidaram com as variações de sentido e o imaginário do mal ao longo da história trazem de volta à nossa época uma nova "angústia do mal". Em particular, após os horrores humanos, políticos e bélicos cometidos no século XX, a angústia do mal seria difratada nas questões das ciências humanas e da filosofia (Watthée-Delmotte \& Deproost, 2000). Para isso, podemos acrescentar que as mudanças causadas pela globalização e pelos avanços tecnológicos reforçaram essa ansiedade, em razão dos comentários catastróficos que foram inseridos nos escritos dos pensadores de nosso tempo.

Na psicologia, não podemos pensar que a manifestação da importância dedicada às ameaças seja um reflexo desse processo? Neste caso, é necessário argumentar não apenas em termos de relações interpessoais e intergrupais, mas também cole- 
tivamente, referindo-se a ameaças que não são apenas uma questão de interação social, mas do curso da história e da evolução do mundo, o que demanda um novo olhar recorrendo a valores para a análise das relações sociais em uma escala humana e temporal mais ampla.

Os entendimentos comuns centrados na interação dos jogos de ameaça estão bem ilustrados nas pesquisas de psicologia social que enfatizam as relações interpessoais ou intergrupais (Caillaud et alii, 2017). No entanto, apresentam conotações que nem sempre são suficientemente levadas em consideração pelas pesquisas que se concentram nos processos cognitivos e sociocognitivos associados à percepção da ameaça em nível individual, mesmo quando se trata de dar conta de atitudes sociais, como no caso da psicologia política.

A definição corrente supõe, além da presença do mal, a intencionalidade por parte da origem/do perpetrador e uma interpretação por parte do alvo/da vítima, a existência de uma forma de contrato social e a antecipação das consequências que podem significar sua ruptura. Essa visão - que se junta à de Hobbes - nem sempre é representada nas pesquisas. Por outro lado, essas pesquisas, centradas na interação, não são capazes de compreender a natureza coletiva de uma ameaça.

Assim, necessitamos distinguir na análise da ameaça a origem/o perpetrador, o alvo/a vítima, a situação, os comentários no espaço público, a fim de determinar as modalidades do perigo que ela representa: qual é o perigo inerente às intenções da origem/do perpetrador, qual modo de ação (simbólico ou material) qualifica o perigo, quais sentimentos (medo, pavor, receio) são os do alvo/da vítima, em que contexto ou situação é a ameaça colocada em jogo, a quais interpretações subjetivas e coletivas ela dá lugar.

Convém aqui propor as especificações a diferenciarem a ameaça em relação ao risco, ampliando mesmo o seu alcance. Embora o risco seja quantificável, previsível e controlável, a ameaça envolve alguma incerteza em sua atualização e imprevisibilidade em seus efeitos. Embora o risco seja definido por condições técnico-científicas e efeitos materiais, a ameaça pode estar localizada e/ou direcionada à esfera ideal (religião, ideologia, projeto político, valores humanos e republicanos etc.). Além disso, as conotações do alvo da ameaça Ihe dão um status de vítima. Moscovici $(2011 ; 2012)$ observou que a atenção dispensada pelas ciências humanas sobre a vitimização está relacionada às exações dos regimes totalitários - sobretudo o nazismo -, mesmo se está em evidência processos similares, através do tempo. Ele enfatiza que a vítima é uma nova figura sobre a qual se pode apontar o aspecto moral da experiência humana. 
Assim, a ameaça está além do alcance da interação e pode apresentar um caráter coletivo, em particular em suas formas mais recentes, em grande parte tingidas de ansiedade. Este último aspecto foi reforçado pelas mudanças provocadas pela globalização e pelo progresso tecnológico, bem como pelos comentários catastróficos que se encontram nos escritos de pensadores do nosso tempo e daqueles que consideram necessário jogar com o "medo heurístico" ou o "catastrofismo esclarecido" para aumentar a consciência e mobilizar as responsabilidades (Baumann, Beck, Jonas, Dupuy, Vidrio etc.).

Esses processos são importantes para a psicologia social, cujos trabalhos sobre ameaças, embora de surgimento recente, permanecem focados nas interações. Será necessário pensar não apenas em termos de relações interpessoais e intergrupais, mas em ameaças que ocorreram e ocorrem no curso da história e da evolução do mundo, com dimensões coletivas e societais.

Nesse cenário, cuja complexidade é aqui delineada em linhas gerais, penso ser importante focar as dimensões que dão às ameaças um tom psicológico específico: o mal que implicam, o medo que suscitam, os sentimentos que provocam entre aqueles que as experimentam ou as observam.

\section{O mal que supõe a ameaça}

A ansiedade do mal - a que me referi anteriormente - encontrou um novo espaço de expressão na literatura pós-moderna acerca dos riscos ambientais, bem como em comentários da mídia e de políticos sobre o terrorismo (Vialles, 2004; Watthée-Delmotte \& Deproost, 2000). Seria possível, a partir dessa constatação, avançar com a percepção de que a ameaça se refere à ideia de "mal social", mal "do" social, mal "para" o social e mal "através/pelo" social. De um lado, alguns estados do mundo ou do meio ambiente, qualificados como ameaçadores, podem ser considerados como o resultado de um mal produzido "pelo" social. De outro lado, certas empresas individuais ou coletivas, por suas implicações prejudiciais, ameaçam com um mal "para" o social. Finalmente, as repercussões dessas situações se traduzem em um estado de mal-estar "do" corpo social.

Dentro dessa perspectiva, uma questão se coloca: em que condições um mal social pode tornar-se uma ameaça para um grupo ou para um indivíduo? Vários casos se apresentam. Pode-se haver identificação de um mal social sem que seja percebido como ameaça, a exemplo do caso das seitas religiosas analisadas por Rouquette (2003, 2007): ou as aceitamos ou as combatemos em função do mal social que representam. Mas não são percebidas como ameaça pessoal por parte das pessoas 
que não compartilham as crenças e as práticas que elas implicam. Esse processo revela um paradoxo da relação individual ou coletiva com a ameaça: é necessário colocar a inevitabilidade de um fenômeno com potencialidades deletérias para que se torne uma ameaça. Estaria aqui em questão a liberdade: o risco do qual não sou livre para fugir torna-se uma ameaça; em contraposição, se eu for livre para não aderir à sua crença, ou para evitar as consequências por meu comportamento, ele não me ameaça. Essa questão de liberdade é operacionalizada em psicologia social e cognitiva sob espécie do controle. Mas também implica em um compromisso psicológico e ético que, ao avaliar uma ameaça real ou potencial para os outros, deve ser estudado. Um movimento nessa direção, no que diz respeito às ameaças terroristas, está emergindo com os trabalhos sobre a desradicalização dos atores sociais mobilizados pelo jihadismo.

Um mal social também pode se referir a um risco objetivo que intervém de maneira massiva, como no caso dos riscos ambientais. Para identificá-lo, é necessário realizar um trabalho de informação e designação pela comunidade através da divulgação de informações científicas, discursos políticos ou de mídia. O caráter ameaçador de um processo ou de um evento é então estabelecido pela gravidade que representa para a comunidade humana ou para o mundo natural; e a natureza do mal que engendra irrompe como pano de fundo dos processos mortificantes para os homens, as espécies vivas, os recursos naturais.

Além da dimensão simbólica do mal - que aparece como objetivamente fundada, na medida em que sempre corresponde a um ataque sofrido por um indivíduo ou um grupo, podendo levar à morte ou à consequente alteração da integridade identitária, psicológica e física da pessoa ou do grupo -, é necessário identificar a especificidade da ameaça em relação a fenômenos com potencial de risco, perigo ou incômodo. Estes são, pelo menos em teoria, objetivos mensuráveis, controláveis por medidas preventivas ou corretivas. A literatura enfatiza então o caráter subjetivo e indefinido, de imprecisão, dessa ameaça, cuja construção social coloca em jogo emoções, sentimentos e interpretações de situações vividas, envolvendo a dimensão temporal da ameaça através da experiência e da memória. Estamos falando aqui de emoções e medo.

\section{O medo que gera a ameaça}

Ficarei aqui limitada ao fator emocional, tomado por central na avaliação das ameaças. Volto-me então ao que chamamos de "medo", cuja análise revela diferentes níveis, que irão constituir hoje uma "cultura do medo" (Riezler, 1944; Delumeau, 1978; Paillard, 1993; Glassner, 2000; Jeudy-Ballini \& Voisenat, 2004). As emoções 
estão presentes como antecipação do mal da ameaça que essa proporciona, de sua experiência por ocasião do dano sofrido, de sua memória para aqueles que a vivenciaram e a reativam na lembrança e da constatação de um efeito objetivo da ameaça. As emoções e os sentimentos mobilizados são de natureza distinta: pavor, medo, reações defensivas, sideração, cólera, rancor etc. O trabalho de elaboração do sentido da ameaça é também diferente: em particular o par medo/ódio intervém após o ocorrido, mesmo se alguém sofreu ou simplesmente observou a concretização da ameaça. É no momento dessa elaboração pós-evento que vão atuar os modelos de interpretação propostos pela cultura e pelas mídias. É nesta fase que uma emoção como o medo pode ser manipulada.

Esse processo havia sido mencionado por Bertrand Russel. Em seu discurso por ocasião do recebimento do Prêmio Nobel de Literatura (1950) - "La portée politique des désirs" ("A abrangência política dos desejos") - Russel referiu-se à relação indissolúvel entre medo e ódio, trazendo as sociedades contemporâneas de volta a um funcionamento de tipo tribal, no que respeita o desconhecido, o estrangeiro e particularmente em suas relações para com os outros, para com os estrangeiros, que são temidos e tratados como inimigos. Sua análise, propriamente psicossociológica, observa a determinação mútua do medo e do ódio e encontra uma aplicação atual nos processos sociais que ocorrem nos usos habituais da ameaça, dentro da comunicação midiática.

Se a relação entre perigo, risco e ameaça é contingente, a relação estabelecida com o medo e o pavor é substancial. O par "ameaça/medo" é indissociável, o que explica o fato de serem termos frequentemente confundidos. Na verdade, é a dimensão do medo que constitui a armadura do sentimento de ameaça; é ela que retira constantemente a atenção dos pesquisadores, e isso por diferentes razões. Sustentáculo do sentimento de ameaça, o medo - ou os medos - que pertence ao campo das emoções - individuais ou socialmente partilhadas (Rimé, 2005) -, é um fenômeno mais puro que a ameaça, associando um estado interno a outro, externo. Para este fim, dispomos de um sólido aparelho teórico, fundado em uma longa tradição de pesquisa. Como emoção, o medo oferece uma oportunidade rara de associar as neurociências à psicologia cognitiva e social, nas esferas individual e coletiva. Além disso, como objeto de discurso social, ele origina uma verdadeira "cultura do medo" (Glassner, 2000), que permite indicar as dimensões sociais cruciais na elaboração das ameaças e sua manipulação política. Enfim, a abordagem do medo permite colocar em relação os processos primários e secundários que regem o pensamento e a ação e estão associados ao domínio das relações sociais e dos processos de formação ou de resolução de conflitos intergrupos (Jarymowicz, 1989; Pereti-Watel Bar Tal, 2006). 
Por ocasião de uma revisão das abordagens sobre o medo na psicologia e nas ciências sociais (Jodelet, 2011a), que foi publicado no Brasil na tradução de meu livro Representações sociais e mundos de vida (2017b) e traduzido na Argentina, na obra Psicologia social y politica, organizada por E. Zubieta, J. Valencia e G. Delfino (2014), consegui identificar relações existentes entre medo e saber, o papel das representações e da "produção de sentido" como "tampa simbólica" contra as ameaças e o medo, as formas outorgadas às ameaças pelas mídias e sua manipulação pelo poder político, seu jogo nas relações intergrupos.

Ilustrei esses processos ao referir-me aos trabalhos sobre a gestão do medo e as ansiedades sociais. Mencionarei aqui os efeitos produzidos pelo medo que a morte desperta na atualidade, ao expor o chamado modelo de gestão do terror (the terror management theory), que trata do papel do medo da morte na mudança de atitudes em relação aos problemas sociais e na defesa de visões de mundo culturalmente estabelecidas (Salomon, Greenberg \& Pyszczynski, 1991). Esta teoria sustenta que, para superar o "paradoxo insolúvel" nascido do desejo de preservar a vida e da certeza da inevitabilidade de sua finitude, os indivíduos se resignam a aderirem a sistemas de crença de tipo místico ou religioso ou encontram refúgio na submissão à autoridade ou ao pertencimento comunitário. Essa teoria encontrou um eco importante após o atentado ao World Trade Center. Além disso, diversos trabalhos (Huddy, 2003; ) puseram em evidência uma tendência nas pessoas com ansiedade difusa a se tornarem menos tolerantes à diferença, mais inclinadas a usarem estereótipos e a mostrarem agressividade diante dos estrangeiros, bem como ao conformismo em face das normas culturais e uma preferência por líderes políticos que afirmem uma forte visão nacionalista, uma vontade de vingança contra os terroristas e até o engajamento nas guerras.

Além disso, diversos autores insistiram especificamente sobre o conluio entre as mídias e as políticas para a eclosão do medo: Glassner (2000), sobre a cultura do medo, Chomsky $(1988,1992)$ sobre a cultura do medo na formatação do consentimento, Al Gore (2004) sobre as políticas do medo, ou cineastas, notadamente Michael Moore. Eles identificaram um certo número de técnicas empregadas para levantar preocupações infundadas e desviar os cidadãos dos problemas sociais reais e da consciência plena de seus problemas. A essa concepção de uma construção midiática e da política dos medos, agrega-se a noção de "medos emergentes" (Furedi, 2005). Esses surgem em um fundo de ansiedade generalizada em razão da falha de "imaginação política", justamente por não se saber como enfrentar questões sociais cruciais e por terem explorada a sensibilidade coletiva inquietante. 
Todos esses modelos focam as consequências que o despertar do medo logra sobre as interações entre os grupos, e sobre a recusa de aceitar as minorias ou os grupos marcados por uma diferença nacional, étnica, racial, religiosa ou sexual. Esse tipo de análise poderia ser aplicado pela forma como a mídia e aqueles que a utilizam para fins políticos tratam as ameaças terroristas, exacerbando o medo, acentuando as rupturas sociais, o risco de ir ao encontro das reações espontâneas às ameaças. Na verdade, há toda uma série de medidas de defesa implantadas por indivíduos ou grupos diante de uma ameaça sobre a qual abordarei agora, mesmo se concisamente.

\section{As respostas à ameaça}

Como no caso de risco, as ameaças exigem e envolvem medidas de evasão. A precaução e a prevenção são as medidas coletivamente preconizadas e sustentadas mesmo quando se trata de colocar em prática comportamentos individuais. Além disso, é a proteção que pode corresponder a uma oferta ou a uma demanda social por segurança.

No plano privado, toda uma série de atitudes ou comportamentos são implantados para evitar a ideia de ameaça. Eles tomam diferentes formas:

- A negação, por meio da qual se apaga a consciência da ameaça que pode estar exposta, como no caso estudado por Fançoise Zonabent, onde as pessoas trabalham ou residem na proximidade de uma central nuclear e que declaram não perceber a ameaça em razão do controle técnico exercido sobre o seu funcionamento.

- O desafio de enfrentar a ameaça para removê-la. Um caso frequentemente encontrado diz respeito às atitudes dos pacientes que sofrem de doenças crônicas ou letais e que recentemente foi ilustrado pelas respostas do público aos atentados quando foi afirmada a vontade de continuar a viver e a curtir a vida como dantes.

- A revolta, por associação aos movimentos de cólera e reprovação coletiva sobre o cenário social, como no caso de lutas em defesa do meio ambiente e contra os riscos agroalimentares.

- A defesa pelo estabelecimento de condutas de proteção: atualmente, há cursos de treinamento em procedimentos de prevenção de risco durante um ataque terrorista, como se projeta a construção de muros para proteger-se da imigração. 
Essas respostas coletivas ou individuais são bastante discutíveis. Em particular as medidas de precaução ou de prevenção, socialmente defendidas, e que foram objeto de debates e de contestação em nome da ansiedade que elas acarretam, da responsabilidade individual que implicam, do controle social que pressupõem e do potencial de resolução que podem gerar (Peretti-Watel \& Moatti, 2009; Bronner \& Gehin, 2010).

Outras reservas resultam do fato de que a validade do conhecimento científico é questionada. Expressas no que se refere às medidas tomadas contra os riscos, essas reservas tomam uma cor particular em relação às ameaças, que implicam uma "coletivização", uma municipalização das preocupações, enquanto o debate sobre ameaças assume um escopo coletivo. Isso é visto em todos os níveis de comunicação social, desde a cena privada das discussões familiares aos meios de tomada de decisões e de políticas ou até a esfera da mídia.

Foi anunciado que os sentimentos anticiência e antiprogresso, o medo de mudanças reapareceram no final do século XX em um clima pacífico, classificando preocupações científicas e expressões de sensibilidade em matéria de riscos e ameaças, em "andaimes de substituição", fórmula tomada de Freud que designaria os sistemas de crenças capazes de confrontar a ansiedade existencial em tempos de paz e de calma social.

Mas já não é o caso hoje, após o agravamento dos alertas climáticos e o aumento do número e da gravidade das incursões terroristas que reforçam as ansiedades e fazem passar dos riscos às ameaças. Especialmente no caso do terrorismo, a forma como os meios de comunicação e os círculos políticos assumem a informação, a interpretam e a utilizam, reforça os medos e leva a consequências negativas para a unidade social. Eles se desviam do trabalho conjunto para enfrentar e superar os sentimentos de ansiedade e ameaça, em favor de conflitos partidários e orientações ideológicas.

Para resumir, podemos isolar os fatores que fazem passar do risco e do perigo à ameaça:

๑ A extensão do dano, que pode chegar até a morte.

๑ A dimensão do mal, que se refere ao imaginário.

- As dimensões emocionais da relação com a ameaça (ansiedade, medo etc.).

๑ A vulnerabilidade do alvo. 
๑ A iminência da possibilidade do surgimento da ameaça.

- Os efeitos sobre a vítima em termos de experiência vivida e processos cognitivos.

- O caráter de punição, retaliação da ameaça, quando há ruptura do contrato social.

- A culpabilização das populações vulneráveis que se tornam uma ameaça.

- As dimensões pessoais colocadas em jogo pela ameaça: imagem de si, identidade social ou pessoal.

Mas quando a vida está em jogo, a questão muda: trata-se de defender uma imagem de si, mas também uma integridade física, moral ou social. Isso dá às ameaças biológicas um status particular que necessita de estudo específico.

São necessários outros elementos para o desenvolvimento completo de um quadro de análise das ameaças, em particular uma classificação das ameaças que leve em conta: os alvos/as vítimas, as origens/os perpetradores, os modos de intervenção, os contextos históricos e sociais. Mas, como o tempo é insuficiente, não é possível aqui dedicar-me às questões que devem ser respondidas para desenvolver de forma aprofundada este quadro de análise.

Espero, pelo menos, que os poucos vislumbres que me foram possíveis oferecer sobre este novo campo de exploração tenham sido esclarecedores e que, no futuro, possam dar origem a novos trabalhos.

\section{Referências}

BOY, D. Le progrès en procès. Paris: Presses de la Renaissance, 1999.

BREAKWELL, G. Models of risk construction: some applications to climate change. Wiley Interdisciplinary Reviews, v. 1, n. 6, p. 857-870, 2010.

BRONNER, G.; GÉHIN, E. L'inquiétant principe de précaution. Paris: Presses Universitaires de France, 2010.

CAILLAUD, S.; BONNOT, V.; DROZDA-SENKOWSKA, E. (Eds.). Menaces sociales et environnementales: repenser la société des risques, p. 17-30. Rennes (FR): Presses Universitaires de Rennes, 2017. 
CHOMSKY, N. Deterring-Democracy. New York: Hill and Wang Press, 1992.

- The culture of terrorism. Boston (MA): South End Press, 1988.

CLAVERIE, E. Techniques de la menace. Terrains, v. 43, p. 13-50, 2004.

CLAVANDIER, G. La mort collective. Pour une sociologie des catastrophes. Paris: Éditions du CNRS, 2004.

DELUMEAU, J. La peur en Occident. Paris: Fayard, 1978.

DUPUY, J. P. Pour un catastrophisme éclairé. Paris: Les Éditions du Seuil, 2002.

FUREDI, Frank. Terrorism and the politics of fear. In: HALE, Chris; HAYWARD, Keith; WAHIDIN, Azrini: WINCUP, Emma (Orgs.). Criminology. Oxford (UK): Oxford University Press, 2005.

GLASSNER, B. The culture of fear. New York: Basic books, 2000.

GORE, Al. The politics offear. Social Research: An International Quarterly, v. 71, n. 4, p. 779-798, Winter 2004.

HUDDY, L. Group membership, ingroup loyalty and political cohésion. In: SEARS, D. O.; HUDDY, L.; JERVIS, R. Handbook of political psychology, p. 511-558. New York: Oxford University Press, 2003.

JARYMOWICZ, M. Próbakonceptualizacjipojęcia "tożsamość": spostrzeganaodrębność JA-INNI jakoatrybutwłasnejtożsamości [Anattempttoconceptualizethenotion "identity": The perceiveddistinctivenessof me-others as anattributeofone'sownidentity]. Przegląd Psychologiczny, v. 32, n. 3, p. 655-669, 1989.

JARYMOWICZ, M.; BAR-TAL, D. The dominance of fear over hope in the life of individuals and collectives. European Journal of Social Psychology, v. 36, p. 367-392, 2006.

JEUDY-BALLINI, M.; VOISENAT, C. Ethnographier la peur. Terrain, v. 43, p. 5-14, 2004.

JODELET, D. Les menaces; passer du mot au concept. In: CAILLAUD, S.; BONNOT, V.; DROZDA-SENKOWSKA, E. (Eds.). Menaces sociales et environnementales: repenser la société des risques, p. 17-30. Rennes (FR): Presses Universitaires de Rennes, 2017a.

- Representações sociais e mundos de vida. Curitiba: Pucpress; Fundaçao Carlos Chagas, 2017b. 
- Représentations sociales et mondes de vie. Paris: Éditions des Archives Contemporaines, 2015a.

- La victimisation vue sous l'angle de la psychologie sociale: I'apport de Serge Moscovici. Sociétés, v. 130, n. 4, p. 41-52, 2015b.

. Dinamicas y formas sociales del miedo. In: ZUBIETA, E.; VALENCIA, J.; DELFINO, G. (Eds.). Psicologia social y politica: enfoches teoricos y estudios empiricos. Buenos Aires: Udeba, 2014.

- Dynamiques sociales et formes de la peur. Nouvelle Revue de Psychosociologie, v. 12, p. 239-256, 2011a.

- Considérations sur le traitement de la stigmatisation en santé mentale. Pratiques en Santé Mentale, v. 2, p. 25-38, 2011 b.

— Formes et figures de l'altérité. In: SANCHEZ-MAZAS, M.; LICATA, L. (Eds.). L'autre. Regards psychosociaux, p. 23-47. Grenoble (FR): Presses Universitaires de Grenoble, 2005.

- Le phénomène Nimby. In: BOYER, M.; HERZLICH, G.; MARESCA, B. (Eds.). L'environnement, question sociale. Dix ans de recherches pour le Ministère de l'Environnement, p. 91-97. Paris: Éditions Odile Jacob, 2001.

- Les représentations sociales et l'étude du rapport Homme/Environnement. In: RIGAS, A. V. D. (Ed.). Social representations and contemporary social problems, p.37-51. Athènes: Ellinika Grammata, 1998.

- Les processus psycho-sociaux de l'exclusion. In: PAUGAM, S. (Ed.). L'exclusion. L'état des savoirs, p. 66-77. Paris: La Découverte, 1996.

- Folies et représentations sociales. Paris: Presses Universitaires de France, 1989.

JODELET, D.; SCIPION, C. Gouverner ou composer avec l'environnement? Le Ministère vu par d'autres administrations à la fin des années 80. In: BARRAQUÉ, B.; THEYS, J. (Eds.). Les politiques d'environnement. Évaluation de la première génération: 1971-1995. Paris: Éditions Recherches, 1998.

- Quand la science met l'inconnu dans le monde. In: THEYS, J.; KALAORA, B. (Eds.). Autrement. «La terre outragée». Série "Sciences en société", v. 1, p. 210-223, 1992. 
JODELET, D.; MONTFORTE, I. L'usage des déchetteries. Pratiques et pratiquants des habitants dans la Communauté Urbaine du Creusot-Montceau les Mines. Paris: Les Éditions de l'Ehess; Écomusée de la Communauté le Creusot Montceau, 1997.

—. Aspects culturels de la participation du public aux politiques d'aménagement de l'environnement. Paris: Écomusée de la Communauté le Creusot Montceau; Ministère de l'Environnement, 1994.

JODELET, D.; MOULIN, P.; SCIPION, C. Représentations, attitudes et motivations face à la gestion des déchets. Autour du phénomène Nimby. Paris: Les Éditions de l'Ehess; Ministère de l'Environnement, 1997.

JODELET, D.; OHANA, J.; BIADI, A.; RIKOU, E. Représentations de la contagion et Sida. Connaissances, représentations, comportements, sciences sociales et prévention du Sida. Bulletin de l'ANRS, p. 87-97, 1994.

KELLEY, H. Common sense psychology and scientific psychology. Annual Review of Psychology, v. 43, p. 22, 1992.

MOSCOVICI, S. The social representation of victims. In: PERMANADELI, R.; JODELET, D.; SUGIMAN, T. (Eds.). Alternative production of knowledge and social representations, p. 43-53; Jakarta: Graduate Program of Euroean Studies; University of Indonesia, 2012.

- An essay on social représentations and ethnic minorities. Social Science Information, v. 50, n. 3-4, p. 442-461, 2011.

PAILLARD, B. (Ed.). Peurs. Communications, n. 57, 1993.

PERETTI-WATEL, P. L'inscription du sentiment d'insécurité dans le tissu urbain. Les Cahiers de la Sécurité Intérieure, n. 39, p. 1-22, 2000.

PERETTI-WATEL, P.; MOATTI, J. P. Le principe de prévention. Le culte de la santé et ses dérives. Paris: Les Éditions du Seuil, 2009.

RIEZLER, K. The social psychology of fear. The American Journal of Sociology, v. 49, n. 6, p. 489-498, 1944.

RIMÉ, B. Le partage des émotions. Paris: Presses Universitaires de France, 2005.

ROUQUeTTE, M. Une taxonomie des peurs collectives. Psicologia, v. 21, n. 2, p. 17-29, 2007.

— (Ed.). Logique sociale des phénomène sectaires. Psychologie et société, 2003. 
SALOMON, S.; GREENBERG, J.; PSYSZCZYNSKI, T. A terror management theory of social behavior: the psychological functions of Self-esteem and cultural wowldviews. In: ZANA, M. P. (Ed.). Advances in expérimental social psychology, p. 9-159. New York: Academic Press, 1991.

THORISDOTTIR, H.; JOST, J. T. Motivated closemindedness médiates the effet of threat on political conservatism. Political Psychology, v. 32, n. 5, p. 785-811, 2011.

VIALLES, N. La peur au ventre? Terrain, n. 43, 2004.

WATthéE-DELMOTTE, M.; DEPROOST, P. A. (Eds.). Imaginaires du mal. Paris: Les éditions du Cerf, 2000.

ZONABEND, F. La presqu'île au Nucléaire. Paris: Éditions Odile Jacob, 1989. 